\title{
Aerosol Observation with Raman LIDAR in Beijing, China
}

\author{
Chen-Bo Xie* and Jun Zhou \\ Key Laboratory of Atmospheric Composition and Optical Radiation, Anhui Institute of Optics and Fine \\ Mechanics, Chinese Academy of Sciences, Hefei 230-031, China \\ Nobuo Sugimoto \\ Atmospheric Environment Division, National Institute for Environmental Studies, Tsukuba 305-8506, Japan \\ Zi-Fa Wang \\ Nansen-Zhu International Research Centre, Institute of Atmospheric Physics, Chinese Academy of \\ Sciences, Beijing 100-029, China
}

(Received June 28, 2010 : revised July 20, 2010 : accepted July 26, 2010)

\begin{abstract}
Aerosol observation with Raman LIDAR in NIES (National Institute for Environmental Studies, Japan) LIDAR network was conducted from 17 April to 12 June 2008 over Beijing, China. The aerosol optical properties derived from Raman LIDAR were compared with the retrieved data from sun photometer and sky radiometer observations in the Aerosol Robotic Network (AERONET). The comparison provided the complete knowledge of aerosol optical and physical properties in Beijing, especially in pollution and Asian dust events. The averaged aerosol optical depth (AOD) at $675 \mathrm{~nm}$ was 0.81 and the Angstrom exponent between $440 \mathrm{~nm}$ and $675 \mathrm{~nm}$ was 0.99 during experiment. The LIDAR derived AOD at $532 \mathrm{~nm}$ in the planetary boundary layer (PBL) was 0.48 , which implied that half of the total AOD was contributed by the aerosol in PBL. The corresponding averaged LIDAR ratio and total depolarization ratio (TDR) were $48.5 \mathrm{sr}$ and $8.1 \%$. The negative correlation between LIDAR ratio and TDR indicated the LIDAR ratio decreased with aerosol size because of the high TDR associated with nonspherical and large aerosols. The typical volume size distribution of the aerosol clearly demonstrated that the coarse mode radius located near $3 \mu \mathrm{m}$ in dust case, a bi-mode with fine particle centered at $0.2 \mu \mathrm{m}$ and coarse particle at $2 \mu \mathrm{m}$ was the characteristic size distribution in the pollution and clean cases. The different size distributions of aerosol resulted in its different optical properties. The retrieved LIDAR ratio and TDR were $41.1 \mathrm{sr}$ and $19.5 \%$ for a dust event, $53.8 \mathrm{sr}$ and $6.6 \%$ for a pollution event as well as $57.3 \mathrm{sr}$ and $7.2 \%$ for a clean event. In conjunction with the observed surface wind field near the LIDAR site, most of the pollution aerosols were produced locally or transported from the southeast of Beijing, whereas the dust aerosols associated with the clean air mass were transported by the northwesterly or southwesterly winds.
\end{abstract}

Keywords : Raman LIDAR, Aerosol, Air pollution, Asian dust

OCIS codes : (280.3640) Lidar; (280.1100) Aerosol detection; (280.1120) Air pollution monitoring; (300.6450) Spectroscopy, Raman

\section{INTRODUCTION}

The increasing urbanization and industrialization of the East Asia region, along with the intense dust storm events occurring mostly in spring time, lead to continuously increasing particulate matter particularly in the lower troposphere [1-2]. The air quality in Beijing is drastically affected by both anthropogenic and naturally occurring dust aerosols. The aerosol properties and their spatial and temporal variations over Beijing - especially during Asian dust events - have been studied lately using ground-based radiometer data [1-3]. However, the quantitative observation with Raman LIDAR is still limited [4]. We added the Raman detection channel into National Institute for Environmental Studies (NIES)

\footnotetext{
*Corresponding author: cbxie@aiofm.ac.cn

Color versions of one or more of the figures in this paper are available online.
} 
LIDAR system in Beijing in December 2007, and took continuous observation until now [5]. This paper reports on the typical results of Raman LIDAR observation from 17 April to 12 June 2008 and their comparison with sun photometer and sky radiometer observations in the Aerosol Robotic Network (AERONET) as well as the surface meteorological observations.

\section{INSTRUMENTATION AND METHOD}

The NIES upgraded Raman LIDAR system is located in the Institute of Atmospheric Physics, Chinese Academy of Sciences in Beijing, China (39.97N, 116.37 E). It operates in a continuous mode (5-min of data acquisition with 10-min intermission) through a window on the roof of the observation room, regardless of weather. The LIDAR system employs two-wavelength laser at $1064 \mathrm{~nm}$ and $532 \mathrm{~nm}$ for detecting two polarization components (parallel and perpendicular polarization) at $532 \mathrm{~nm}$, nitrogen Raman shifted scattering at $607 \mathrm{~nm}$ and elastic scattering at $1064 \mathrm{~nm}$. Though the signals from the Raman channel were recorded both in the day and night, only nighttime data were used in the analysis because of the large background radiation in the daytime. Based on these LIDAR data, aerosol optical properties included extinction and backscatter coefficients, LIDAR ratio and total depolarization ratio (TDR) at $532 \mathrm{~nm}$ were derived in the night time. The detailed method to retrieve aerosol optical properties from the Raman LIDAR data was described in the previous paper [5]. Here we only focus on the observed results by Raman LIDAR and their comparison with aerosol measurements in AERONET and the surface meteorological observations.

The sun photometer and sky radiometer observations were performed in AERONET located in Beijing (39 58' $37^{\prime}$ ' $\mathrm{N}$, 116 22' 51''E). The daily aerosol optical depth (AOD) and other AOD-dependent products are derived from the level 2.0 data (cloud-screened and quality-assured). The daily meteorological parameters are observed at the ZBAA station in Beijing. The Air Pollution Index (API) is measured from 1200 LT of the previous day to 1200 LT of the current day, and reported from the Beijing Municipal Environmental Protection Bureau. To determine this API, four chemical substances ( $\mathrm{SO} 2, \mathrm{NO} 2, \mathrm{CO}$, and $\mathrm{O} 3)$ and the particulate matter concentration (PM10) are measured; the highest value of these five parameters becomes the API. In China and especially in Beijing PM10 seems always to have been the highest of the five parameters, which means the aerosol particle is the main contribution to API values. Thus the value of API indicates the concentration of particle matter in principle.

\section{RESULTS AND DISCUSSIONS}

Figure 1 (a) to (c) gives the continuous measurements of

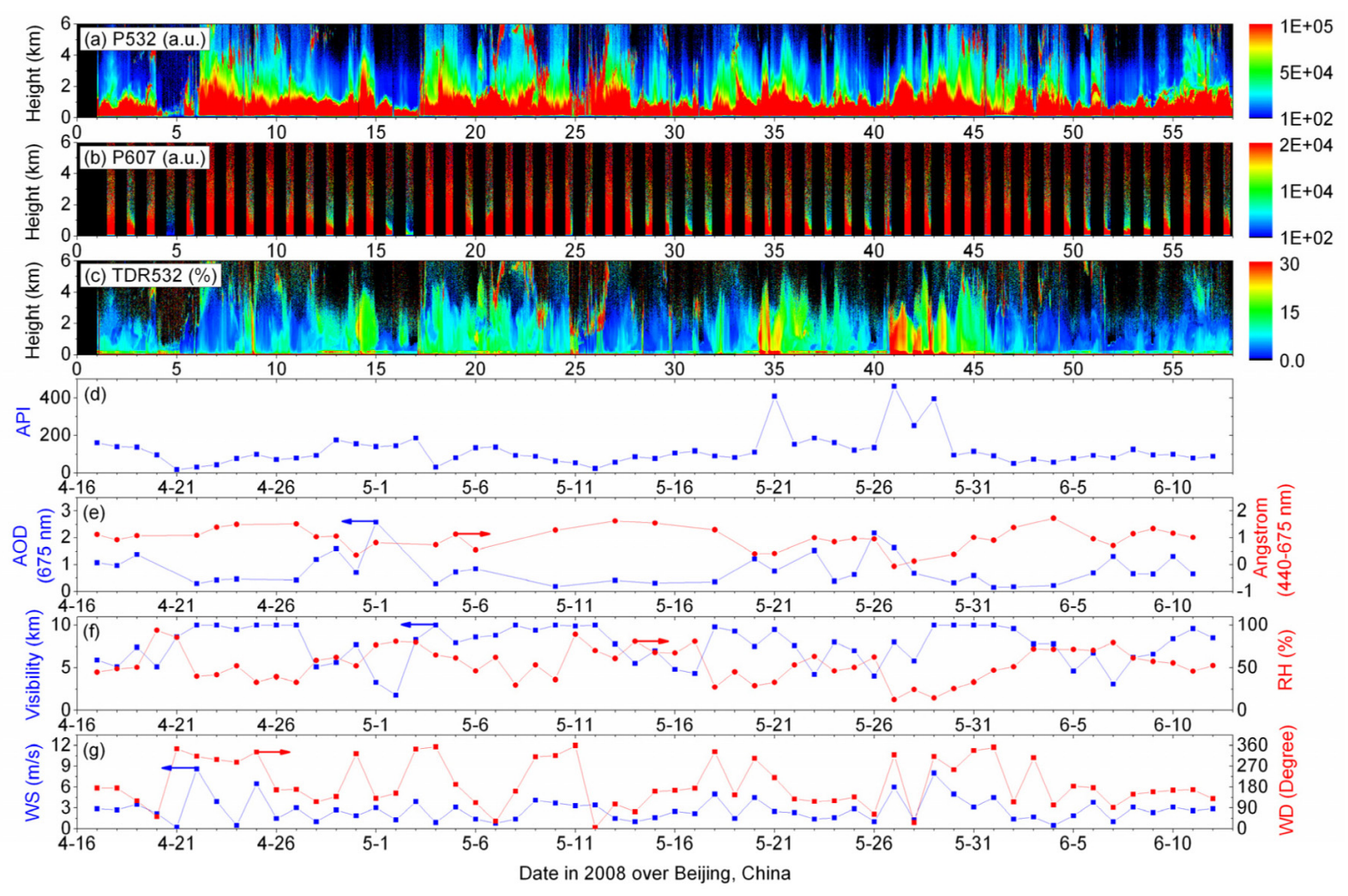

FIG. 1. Time-to-height indication of (a) the range-corrected backscatter intensity at $532 \mathrm{~nm}$ and (b) Raman shifted scattering intensity at $607 \mathrm{~nm}$ and (c) the TDR at $532 \mathrm{~nm}$. The simultaneous observations of (d) API, (e) AOD and Angstrom exponent, (f) surface visibility and relative humidity-RH as well as (g) wind speed-WS and wind direction-WD are presented. 
aerosol optical properties with Raman LIDAR in Beijing from 17 April to 12 June 2008. Although the range-corrected backscattering intensity at $532 \mathrm{~nm}$ (a) and Raman shifted scattering intensity at $607 \mathrm{~nm}$ (b) in arbitrary units have no clear physical meaning, it is useful to see the full vertical structure of the aerosol in the atmosphere. The TDR at 532 $\mathrm{nm}(\mathrm{c})$ reflects the non-sphericity of the scatterers and is an indicator for identification of ice clouds and dust particles. Figure 1 (d) shows the daily API variation, indicating the content of pollution and dust aerosols near the surface. Figure 1 (e) gives the daily AOD at $675 \mathrm{~nm}$ and Angstrom exponent (440-675 nm) observed by the sun photometer in AERONET. Figure 1 (f) to (g) present the daily meteorological parameters during the LIDAR experiment.

On the whole, we can find that there was a close association between Raman LIDAR, sun photometer and surface observations, especially during Asian dust events which occurred on 30 April, 20 to 21 May and 27 to 29 May. The averaged API was 124.3, corresponding to the larger than $0.15 \mathrm{mg} / \mathrm{m}^{3}$ for PM10 mass concentration. The maximal value of $463\left(0.5-0.6 \mathrm{mg} / \mathrm{m}^{3}\right)$ on 27 May indicates the occurrence of a heavy dust event. The averaged AOD and the Angstrom exponent were 0.81 and 0.99 during the experiment. The minimum value of the Angstrom exponent was -0.06 on 27 May, indicating the larger dust particles on that day. The simultaneously observed meteorological parameters provide useful information to reveal the ambient conditions of the pollution and dust aerosols and their probable sources.

Figure 2 gives the daily variation of aerosol optical properties which includes AOD, averaged aerosol extinction, LIDAR ratio and TDR in the planetary boundary layer (PBL). Sun photometer derived AOD are presented in figure 2 for comparison. These values of AOD are correlated well as a whole, and the disagreement is mainly due to the different observation time, the different wavelength and the different integrated height. The averaged AOD during the period of the experiment was $0.81 \pm 0.57$ at $675 \mathrm{~nm}$ for sun photometer measurement and $0.48 \pm 0.34$ at $532 \mathrm{~nm}$ for Raman LIDAR measurement. Aerosol in PBL contributed about half to the AOD values in total atmosphere, indicating larger amount

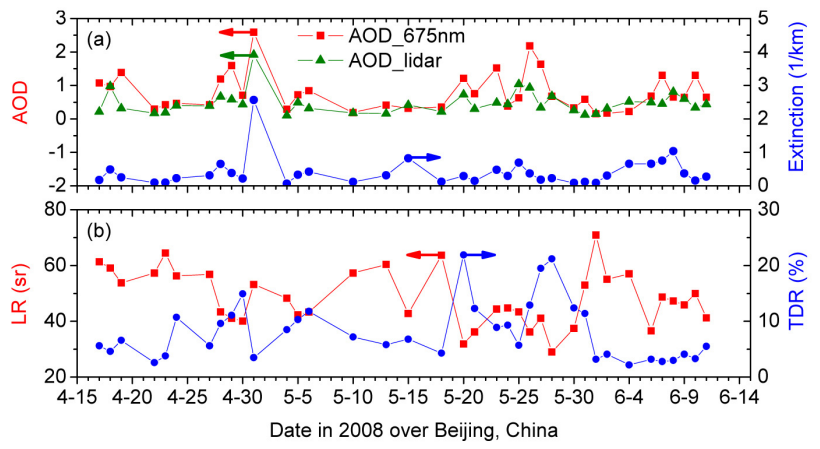

FIG. 2. Temporal evolution of (a) AOD measured by the sun photometer and Raman LIDAR as well as the averaged aerosol extinction, (b) LIDAR ratio and TDR in PBL. of aerosols existed in PBL over Beijing city. LIDAR derived aerosol extinction varied from $0.07 \mathrm{~km}^{-1}$ (4 May) to 2.56 $\mathrm{km}^{-1}$ (1 May), and the average value was $0.40 \pm 0.44 \mathrm{~km}^{-1}$. The large standard deviation of aerosol extinction demonstrates the large temporal variation of aerosols in PBL.

The LIDAR ratio during the experiment was in the range between 29.0sr (28 May) and 70.9sr (1 June), and the average value was $48.5 \pm 9.9 \mathrm{sr}$, which is close to the mean value of 46.7 $\pm 5.6 \mathrm{sr}$ found in south China [6]. The corresponding TDR was $8.1 \pm 5.2 \%$ with the minimal value of $2.2 \%$ (4 June) and the maximum value of $21.9 \%$ (20 May). There seems to have been a negative correlation between LIDAR ratio and TDR. One possible explanation is that the high value of TDR indicates the occurrence of a dust event, and the large dust particles decrease the LIDAR ratio. We applied the TDR of $10 \%$ as the threshold value for determining the dust particles and spherical aerosols. The result demonstrates that dust events occurred in 12 days during the 37-day experiment, and no dust events in 25 days. The averaged LIDAR ratio, TDR and extinction coefficient in dust events were $40.7 \pm 7.8 \mathrm{sr}, 14.2 \pm 4.2 \%$ and $0.25 \pm 0.11 \mathrm{~km}^{-1}$, respectively. The LIDAR ratio was consistent with the previous observation for Asian dust particles [7-8]. The corresponding values for no dust event days were $52.3 \pm 8.6 \mathrm{sr}, 5.2 \pm 2.2 \%$ and $0.47 \pm$ $0.51 \mathrm{~km}^{-1}$. The enhanced LIDAR ratio was associated with the small particles and the light-absorption aerosols. The bigger aerosol extinction for no dust events than for dust events suggests that the effect of spherical aerosol mostly produced by anthropogenic sources on air quality in Beijing is greater than that of the dust particles.

Figure 3 gives the representative volume size distributions in the air columns for dust, pollution and clean case. We can see that the coarse mode radius is commonly located around $3 \mu \mathrm{m}$ in the dust case, which is consistent with previous reports on the size of Asian dust [7-8]. The retrieved AOD at $675 \mathrm{~nm}$ was 1.64 and the Angstrom exponent was -0.06 , the LIDAR ratio and TDR were $41.1 \mathrm{sr}$ and $19.5 \%$, respectively. A distinctive fine mode centered near $0.2 \mu \mathrm{m}$ is seen in the size distribution for the pollution case, which is characteristic of an urban polluted atmosphere. A coarse mode located near $2 \mu \mathrm{m}$ is also seen in the pollution case.

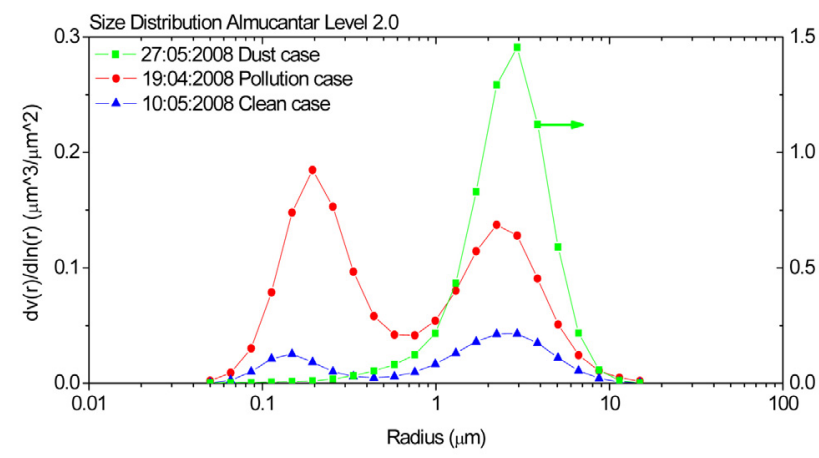

FIG. 3. Representative volume size distributions of aerosol retrieved from the sun photometer sky radiometer in AERONET. 

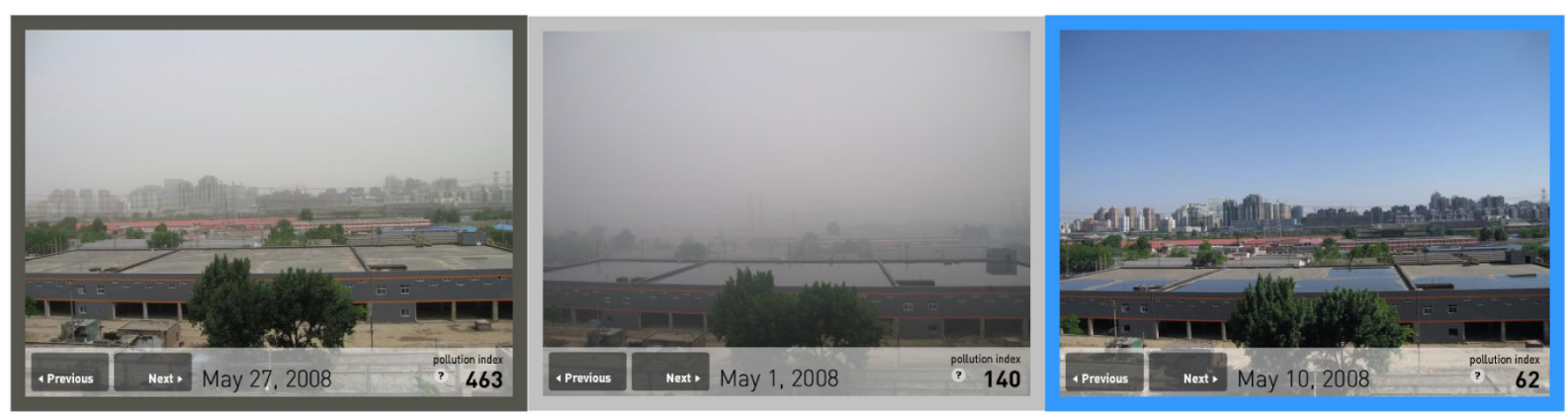

FIG. 4. Photos in dust (27 May 2008), pollution (1 May 2008) and clean (10 May 2008) cases during Raman LIDAR experiment in Beijing.
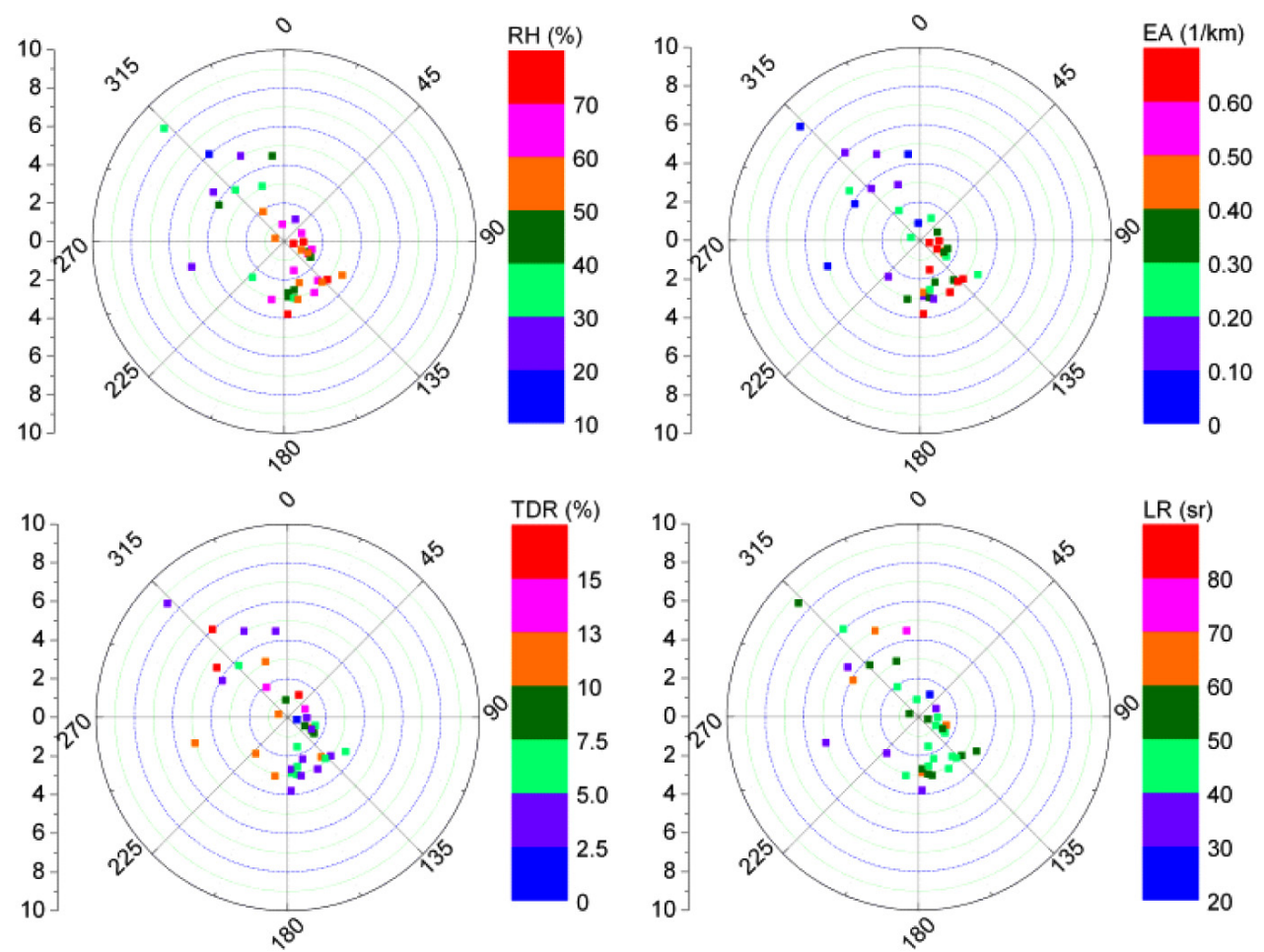

FIG. 5. The variation of relative humidity-RH, aerosol extinction-EA, total depolarization ratio-TDR and LIDAR ratio-LR as a function of wind speed and direction.

It reflects the presence of large particles which are probably the residue of a dust event or the production of incomplete combustion. The bi-mode size distribution which we have observed is frequently found in the pollution case in Beijing city [9-11]. The corresponding AOD was 1.38, Angstrom exponent 1.08, LIDAR ratio 53.8sr and TDR 6.6\%. Although the bi-mode is seen in the size distribution of the clean case, the low volume concentration of aerosol particles indicated improved air quality. The AOD on that day was 0.22 and Angstrom exponent was 1.74. The LIDAR ratio and TDR were $57.0 \mathrm{sr}$ and $2.2 \%$, respectively. The photos in dust (27 May 2008), pollution (1 May 2008) and clean (10 May 2008) cases are shown in figure 4 for depicting the air quality visually in Beijing. The value in the bottom right of photos is the API. It is interesting that the worst air quality does not happened for the dust case which has the biggest API (463), but for the pollution case with the middle API (140). It suggests that the observation of API or the mass concentration of particles is not enough to describe the real air quality in Beijing. The Raman LIDAR observation is required and effective supplement to monitor the air quality in Beijing.

Figure 5 shows the variation of $\mathrm{RH}$, aerosol extinction, TDR and LIDAR ratio as a function of wind speed and direction. It is easy to find that the southeasterly wind and northwesterly wind prevailed during the period of the experiment. For the southeasterly wind or weak wind, most of RH was greater than $50 \%$, aerosol extinction was larger than $0.2 \mathrm{~km}^{-1}$, TDR was less than $10 \%$ and LIDAR ratio ranged between $40 \mathrm{sr}$ and $60 \mathrm{sr}$. It implies the anthropogenic 
aerosol was produced locally or transported from the southeast of Beijing city. For the northwesterly wind, there were two different cases. One is the clean air case with RH of 20-50\%, aerosol extinction less than $0.2 \mathrm{~km}^{-1}$, TDR smaller than $5 \%$ and LR from $50 \mathrm{sr}$ to $80 \mathrm{sr}$. The other is the dust case with RH $10-40 \%$, aerosol extinction less than $0.3 \mathrm{~km}^{-1}$, TDR larger than $10 \%$ and LR ranged between $30 \mathrm{sr}$ and 50sr. Beside the northwesterly wind, figure 5 demonstrates that some dust events were transported by the southwesterly wind to Beijing city. Similar to the results provided by photos in figure 4, figure 5 also indicates that the worst air quality with high value of aerosol extinction (EA) does not appear in the dust cases. The information in figure 5 is very useful to determine the probable sources of air pollution and dust aerosols in Beijing.

\section{CONCLUSION}

The continuous observation with Raman LIDAR at the Beijing site of NIES LIDAR network gave the high spatial variability of aerosol vertical structure and its optical properties such as AOD in PBL, LIDAR ratio and TDR. High TDR obviously resulted from the occurrence of dust events, and high AOD in PBL resulted from the impact of pollutant particles in Beijing. The LIDAR ratio decreased with TDR which implies the small LIDAR ratio mostly associated with the nonspherical and large aerosol, namely dust particles. The retrieved LIDAR ratio and TDR during the experiment were $41.1 \mathrm{sr}$ and $19.5 \%$ for dust events, $53.8 \mathrm{sr}$ and $6.6 \%$ for pollution events as well as $57.3 \mathrm{sr}$ and $7.2 \%$ for clean events. The correlation between the LIDAR ratio and the particle size is proved by the sun photometer and sky radiometer observation at the Beijing site in AERONET. The volume size distribution showed the presence of two modes for different atmospheric conditions, one accumulation mode with median radius $3 \mu \mathrm{m}$ for the dust case, and bimode with fine particles centered at $0.2 \mu \mathrm{m}$ and coarse particles at $2 \mu \mathrm{m}$ for pollution and clean cases. The value of the volume size distribution at $3 \mu \mathrm{m}$ in the dust case was obviously larger than the values in the pollution and clean cases. Using the observed surface wind field near the LIDAR site, it is found that most of the pollution aerosols were produced locally or transported from the southeast of Beijing, whereas the dust aerosols associated with the clean air mass were transported by the northwesterly or southwesterly wind.

The results above demonstrate that the Raman LIDAR is a very useful tool to observe the temporal variability of aerosol as well as to determine the aerosol types and their sources in conjunction with the data by instruments in AERONET and the surface observations. Beside the Beijing site, two LIDAR systems in Guangzhou and Hefei were upgraded to Raman LIDARs for quantitative and continuous observation of the local aerosol. Moreover, the new polarization and Raman LIDAR system is being developed for the Chinese Academy of Meteorological Sciences and will be installed in Beijing for monitoring the pollutant and dust aerosols in automatic and continuous operation in Oct. 2010. Because both the detecting range and the observing precision of the new Raman LIDAR system will be improved greatly over the one used in the NIES LIDAR network, it will provide detailed and comprehensive information about aerosols in Beijing for better understanding of their impact on the atmosphere and environment.

\section{ACKNOWLEDGMENT}

This research was supported by the Global Environmental Research Fund of the Ministry of the Environmental, Japan and the Open Research Fund of Key Laboratory of Atmospheric Composition and Optical Radiation, Chinese Academy of Sciences, China. The sun photometer and sky radiometer observed data used in this paper were produced from AERONET database at http//:aeronet.gsfc.nasa.gov. We thank researchers and their efforts for establishing and maintaining instruments at the Beijing site, and two anonymous reviewers for useful comments and suggestions.

\section{REFERENCES}

1. T. F. Eck, B. N. Holben, O. Dubovik, A. Smirnov, P. Goloub, H. B. Chen, B. Chatenet, L. Gomes, X. Y. Zhang, S. C. Tsay, Q. Ji, D. Giles, and I. Slutsker, "Columnar aerosol optical properties at AERONET sites in central Eastern Asia and aerosol transport to the tropical Mid-Pacific," J. Geophys. Res. 110, D06202, doi:10.1029/2004JD005274 (2005).

2. T. Cheng, H. Wang, Y. Xu, H. Li, and L. Tian, "Climatology of aerosol optical properties in Northern China," Atmos. Environ. 40, 1495-1509 (2006).

3. X. A. Xia, H. B. Chen, P. C. Wang, W. X. Zhang, P. Goloub, B. Chatenet, T. F. Eck, and B. N. Holben, "Variation of column-integrated aerosol properties in a Chinese urban region,” J. Geophys. Res. 111, D05204, doi:10.1029/2005JD 006203 (2006).

4. M. Tesche, A. Ansmann, D. Müller, D. Althausen, R. Engelmann, M. Hu, and Y. Zhang, "Particle backscatter, extinction, and LIDAR ratio profiling with Raman LIDAR in South and North China," Appl. Opt. 46, 6302-6308 (2007).

5. C. Xie, T. Nishizawa, N. Sugimoto, I. Matsui, and Z. Wang, "Characteristics of aerosol optical properties in pollution and Asian dust episodes over Beijing, China,” Appl. Opt. 47, 4945-4951 (2008).

6. A. Ansmann, R. Engelmann, D. Althausen, U. Wandinger, M. Hu, Y. Zhang, and Q. He, "High aerosol load over the pearl river delta, China, observed with Raman LIDAR and sun photometer," Geophys. Res. Lett. 32, L13815 (2005).

7. Z. Liu, N. Sugimoto, and T. Murayama, "Extinction-tobackscatter ratio of Asian dust observed with high-spectralresolution LIDAR and Raman LIDAR,” Appl. Opt. 41, 2760-2767 (2002).

8. T. Murayama and M. Sekiguchi, "Intercomparison of aerosol 
optical properties observed by LIDAR, sun/sky photometers and surface in situ measurements during Asian dust event in Tokyo, Japan," in Proc. The 24th International Laser Radar Conference (Boulder-Colorado, USA, June 2008), pp. 943-946.

9. X. Yu, B. Zhu, and M. Zhang, "Seasonal variability of aerosol optical properties over Beijing," Atmos. Environ. 43, 40954101 (2009).

10. H. Che, G. Shi, A. Uchiyama, A. Yamazaki, H. Chen, P.
Goloub, and X. Zhang, "Intercomparison between aerosol optical properties by a PREDE skyradiometer and CIMEL sunphotometer over Beijing, China," Atmos. Chem. Phys. 8, 3199-3214 (2008).

11. S. Kim, S. Yoon, J. Kim, and S. Kim, "Seasonal and monthly variations of columnar aerosol optical properties over East Asia determined from multi-year MODIS, LIDAR, and AERONET sun/sky radiometer measurements," Atmos. Environ. 41, 1634-1651 (2007). 